Trab. Ling. Aplic., Campinas, 45(1): 55-73, Jan./Jun. 2006

\title{
UM OLHAR CRÍTICO SOBRE O ENSINO DE VOCABULÁRIO EM CONTEXTOS DE INGLÊS COMO LÍNGUA ESTRANGEIRA
}

\author{
DANIEL FERNANDO RODRIGUES \\ UNESP
}

\begin{abstract}
RESUMO
Este trabalho resume os resultados obtidos em minha dissertação de mestrado, que tem por objetivo analisar a relação entre o ensino de vocabulário, as estratégias de aprendizagem e a produção oral de alunos de inglês como língua estrangeira. A princípio, foi feito um estudo com o objetivo de obter uma visão geral sobre o ensino do vocabulário em contextos diferentes. Com base nesse estudo, escolheu-se um grupo para participar de um estudo de caso, cujo objetivo era analisar o ensino de vocabulário e as estratégias de aprendizagem à medida que apareciam nas aulas, assim como seu efeito na produção oral dos alunos. Os resultados mostram que a abordagem usada pelo professor para ensinar o vocabulário, que era basicamente explicar o significado das palavras para solucionar as dificuldades de compreensão, não ajuda os alunos a adquirirem tais palavras para uso produtivo. Com o objetivo de melhorar a variação e o perfil lexicais dos alunos, faz-se necessário utilizar uma abordagem que trabalhe o vocabulário com objetivos produtivos e que enfoque a prática da língua, tanto em relação à produção quanto à compreensão orais.
\end{abstract}

Palavras-chave: ensino de vocabulário; estratégias de aprendizagem; produção oral em ILE.

\begin{abstract}
This paper summarizes the results achieved in my MA dissertation. It aims at analyzing the relationship between vocabulary teaching and learning strategies and EFL students' oral production. At first, a study aiming at giving an overview of how vocabulary was being dealt with in different contexts was carried out. Based on this study, a group was chosen to participate in a case study whose objective was to analyze the teaching of vocabulary and learning strategies as they occurred in classes, as well as their effect on the students' oral production. Results show that the approach used by the teacher to deal with vocabulary, which was basically to explain the meaning of words to cope with difficulties in comprehension, does not help students to retain such words for productive use. In order to improve students' lexical profile and lexical variation, it is necessary to use an approach that deals with vocabulary with productive goals and targets at language practice both in oral production and comprehension.
\end{abstract}

Key-words: vocabulary teaching; learning strategies; EFL oral production.

\section{INTRODUÇÃO}

Este artigo tem como objetivo fazer uma síntese dos resultados apresentados em minha dissertação de mestrado intitulada "O ensino de vocabulário em aulas de inglês como língua estrangeira: foco na produção oral ${ }^{1}$ ". Conforme consta na literatura, o

\footnotetext{
${ }^{1}$ A pesquisa contou com apoio financeiro da FAPESP (Processo 00/03808-9).
} 
vocabulário tem sido uma área um tanto negligenciada na pesquisa em Lingüística Aplicada (FOLSE, 1998; BOWEN; MARKS, 1994; MEARA, 1984). Em sala de aula, o vocabulário também tem sido colocado em segundo plano, não recebendo nenhuma atenção especial, mesmo sendo um dos principais fatores responsáveis pelas dificuldades dos alunos em se expressar em LE.

O vocabulário, em geral, tem sido tratado apenas como um "coadjuvante" na sala de aula, não recebendo nenhuma atenção especial, mesmo sendo, segundo os próprios alunos, um dos principais fatores responsáveis por suas dificuldades durante as interações verbais. Segundo Meara (1984),

\begin{abstract}
Os próprios alunos são os primeiros a identificar os problemas lexicais como sendo sua maior fonte de problemas na segunda língua, e esta auto-avaliação é sustentada por grandes coletas de erros que - como o corpus Utrecht - mostram, de maneira consistente, que os erros lexicais superam os erros gramaticais na razão de três ou quatro por um². (p. 229)
\end{abstract}

Nos últimos anos, contudo, foi possível verificar um crescente interesse, tanto de pesquisadores estrangeiros (NATION, 2001; LAUFER, 1994, 1995, 1998; McCARTHY, 1990; MEARA, 1984; entre outros) quanto brasileiros, pelo estudo do vocabulário (SCARAMUCCI, 1995; GATTOLIN, 1998; LEFFA, 2000; ZILLES, 2001; entre outros). Considerando que a maior parte da pesquisa existente em vocabulário até o momento tem como foco a compreensão e produção escritas, o presente estudo se justifica por somar-se a outros poucos trabalhos que enfocam a oralidade, no escopo do ensino e aprendizagem de língua estrangeira.

Diante da necessidade de preenchimento dessa lacuna, o objetivo deste estudo é analisar a relação existente entre as estratégias de ensino e de aprendizagem de vocabulário e a produção oral de alunos de ILE. Além disso, pretende-se traçar um perfil de como o vocabulário está sendo trabalhado em sala de aula, analisar o grau de desenvolvimento lexical dos alunos na sua produção oral no decorrer do curso, e fornecer encaminhamentos e sugestões para o ensino de vocabulário.

\title{
1. METODOLOGIA
}

Esta pesquisa combina procedimentos qualitativos e quantitativos. O uso da análise quantitativa fez-se necessário para a análise dos questionários da fase de mapeamento da pesquisa e também para a análise dos resultados de alguns testes aplicados aos alunos, com o objetivo de mapear a extensão e profundidade de seu vocabulário. A estatística é utilizada como forma de validar e confrontar esses dados que, posteriormente, foram analisados qualitativamente, junto aos dados obtidos com o auxílio dos outros instrumentos de pesquisa.

\footnotetext{
${ }^{2}$ No original: "Learners themselves, for instance, are very quick to identify lexical problems as their greatest single source of difficulty in the L2, and this self-assessment is borne out by the fact that large collections of errors - such as the Utrecht corpus - consistently show lexical errors outnumbering grammatical erros by three or four to one."
} 
Na primeira fase da coleta, para realização do estudo exploratório, foram observados seis grupos, representantes de três contextos de ensino diferentes. No primeiro contexto, duas escolas particulares de ensino médio, observei duas turmas do segundo ano. Em uma dessas escolas, os alunos eram submetidos, no início do semestre, a uma prova de classificação para definição do nível da turma. As turmas das aulas de inglês eram formadas de acordo com a classificação dos alunos no teste de classificação. O objetivo da escola era fazer com que as turmas fossem menos heterogêneas e que os alunos pudessem aprender a língua inglesa como se estivessem em uma escola de idiomas. A turma indicada para a coleta de dados era do segundo ano e utilizava um material didático de nível intermediário (New Interchange 2). Para que pudesse realizar uma análise comparativa entre os dois contextos de ensino médio, optei por analisar o segundo ano de uma outra escola, que também utilizava um material didático de semelhante (Triple Jump 2).

O segundo contexto foi o de escolas de idiomas, sendo uma delas a escola onde eu lecionava e a outra uma escola que, de acordo com a coordenadora pedagógica, utilizava uma metodologia "diferente" e "moderna", baseada na teoria das inteligências múltiplas de Gardner (1994). Nas escolas de idiomas, o parâmetro utilizado para a definição do nível intermediário se baseou na própria classificação dos alunos pelas escolas analisadas.

O terceiro e último contexto foi o universitário. Coletei dados em duas turmas diferentes de uma mesma professora. A professora se mostrou bastante receptiva e escolheu pessoalmente os grupos que considerava de nível intermediário, dentre os que ela lecionava, uma vez que na universidade não há a mesma classificação explícita de nível de proficiência que se verifica nas escolas de idiomas. Para fazer tal seleção, a professora se baseou no resultado que os alunos tiveram no Oxford Placement Test (OPT) que tinha sido aplicado por ela no início do ano. Nesse contexto, foram observadas as aulas da disciplina Língua Inglesa II (da turma do segundo ano de Licenciatura em Letras) e Língua Inglesa IV (da turma do quarto ano de Licenciatura em Letras).

Os instrumentos de pesquisa utilizados foram gravações de aulas em áudio e vídeo, entrevistas com alunos e professores, diários de classe feitos pelo professor, pesquisador e pelos alunos, e questionários. Além disso, foram aplicados testes de proficiência, exames orais e um inventário sobre estratégias de aprendizagem. Inicialmente foi feito um estudo exploratório para observar como o vocabulário era trabalhado em diferentes contextos e quais eram as crenças dos participantes desses contextos com relação a esse trabalho. Para esse estudo exploratório foram observadas de quatro a oito aulas de cada um dos contextos onde os dados foram coletados.

Com base nesse estudo, foi selecionada uma classe para a realização de um estudo de caso com o objetivo de verificar o uso das estratégias de ensino e aprendizagem de vocabulário à medida que ele aparecia nas aulas, e seu reflexo na produção oral dos alunos. A coleta dos dados para a realização do estudo de caso teve a duração de um semestre letivo e as interações de sala de aula foram os dados primários utilizados para a análise, uma vez que o foco desta pesquisa é a oralidade.

Na seção a seguir, descrevo mais detalhadamente cada um dos estudos, apresento a análise e a discussão sobre os dados coletados e discuto brevemente alguns dos resultados obtidos. 
RODRIGUES - Um olhar crítico sobre o ensino de vocabulário...

\section{ESTUDO EXPLORATÓRIO}

A fim de descrever as crenças dos alunos e professores, apresento a análise de algumas questões mais pertinentes dos questionários por eles respondidos. A análise das respostas fornecidas pelos alunos permite afirmar que, embora os contextos pesquisados apresentem diferenças entre si, há uma certa homogeneidade no que se refere às crenças dos alunos e dos professores quanto ao ensino e ao estudo do vocabulário. Passo a discutir, a seguir, as questões selecionadas.

Analisando as respostas da pergunta 4 (Figura 1), percebemos que 50\% dos alunos pesquisados consideram o vocabulário como sendo o fator que lhes traz mais dificuldades no momento de expressarem suas opiniões em LE. Alguns alunos declararam que, por não conhecerem as palavras que precisam para dizer o que querem, acabam não falando durante as aulas. Reconheço que, na maioria das vezes, não é possível, para o aluno, saber todas as palavras que necessita para expressar o que quer. Reconheço também que é necessário que o aluno seja capaz de utilizar estratégias de compensação para solucionar essa falta de conhecimento. No entanto, pude perceber que, muitas vezes, os alunos têm que desempenhar uma tarefa na qual devem discutir sobre algum assunto específico, cujo vocabulário básico lhes é desconhecido. Em uma de suas aulas, por exemplo, P pede para os alunos descreverem o cômodo preferido da casa deles. A maioria dos alunos, no entanto, não dominava o vocabulário básico de mobília e, por isso, ou falaram em português, ou ficaram sem falar.

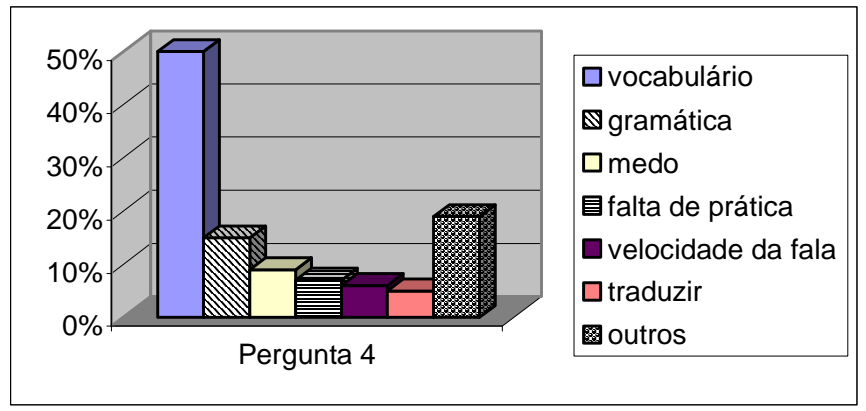

Figura 1: No momento da conversação em língua estrangeira, qual é o fator que lhe traz mais dificuldades para expressar suas opiniões?

A fim de saber o que o aluno busca em seu curso de inglês, foi perguntado o que ele considera fundamental aprender durante suas aulas (Figura 2). Foi constatada que a oralidade é a principal preocupação dos alunos atualmente, uma vez que $44 \%$ deram respostas como "conversação", "falar a língua", ou "expressão oral", que foram todas agrupadas no gráfico como "conversação". Os alunos alegam que com os efeitos da globalização e a necessidade 
de se ter inglês fluente para o mercado de trabalho faz-se necessário aprender a se expressarem oralmente. Esse aspecto, no entanto, nem sempre é trabalhado em sala de aula.

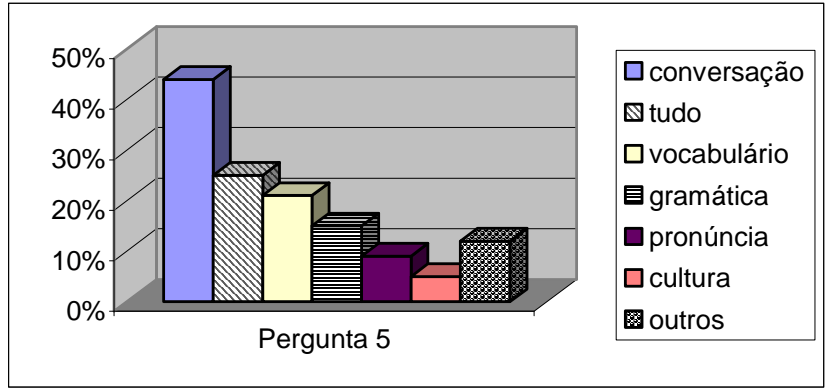

Figura 2: O que é fundamental aprender em uma aula de língua inglesa?

Duas questões do questionário enfocam diretamente o estudo de vocabulário pelos alunos perguntando como e com que freqüência eles estudam vocabulário (Figura 3 e 4). De acordo com as repostas, pode-se dizer que quase metade dos alunos não tem como hábito estudar o vocabulário. Ao verificar as respostas para a pergunta 8 (Figura 4), percebese que menos de $20 \%$ dos alunos dizem estudar o vocabulário de uma aula para outra. Portanto os alunos, em geral, não têm o hábito de estudar o vocabulário regularmente, o que pode contribuir para que o vocabulário seja citado como a maior fonte de problemas para a comunicação em inglês.

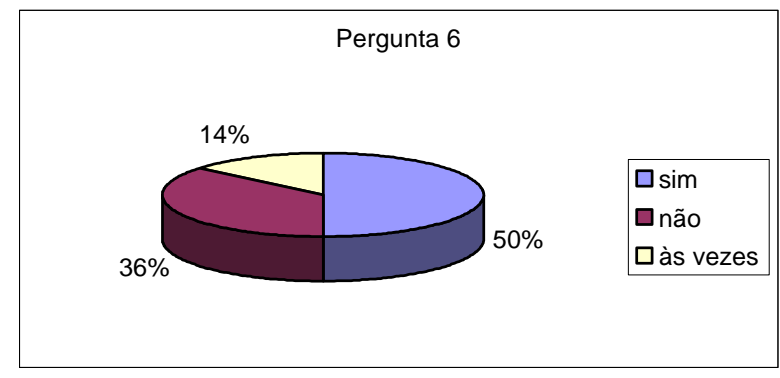

Figura 3: Você estuda vocabulário? 
RODRIGUES - Um olhar crítico sobre o ensino de vocabulário...

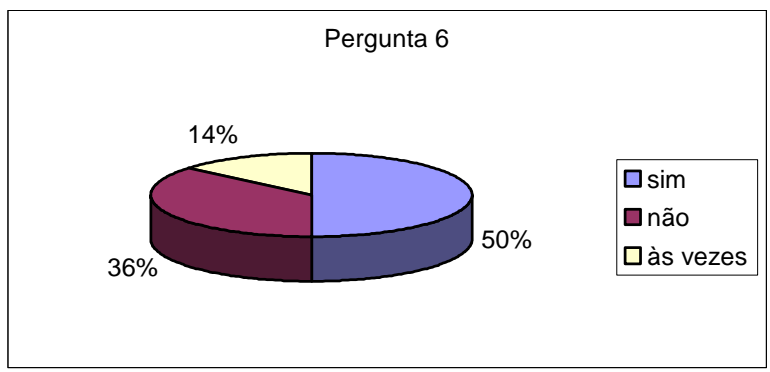

Figura 4: Você, geralmente, estuda o vocabulário de uma aula para a outra?

Pôde-se perceber que um dos fatores que leva os alunos a não estudar o vocabulário é exatamente a falta de estratégias adequadas, já que eles simplesmente não sabem como fazê-lo. Sem orientação alguma do professor, acabam recorrendo aos meios tradicionais e, por conseguinte, se desmotivando. Muitos alunos disseram não estudar inglês por acharem "muito chato" decorar ou ficar repetindo as listas de palavras.

Para as professoras, o vocabulário também não é tratado com tanta importância, uma vez que não recebe um enfoque especial em nenhum dos contextos, com exceção de uma das aulas do contexto universitário. Geralmente, as professoras explicam o vocabulário quando o aluno não entende alguma palavra e pede uma explicação, ou quando elas próprias supõem que os alunos desconheçam determinada palavra e decidem explicá-la. Em todos os contextos, a paráfrase e a tradução são as estratégias mais utilizadas para ensinar o vocabulário. A paráfrase é mais freqüente entre os alunos que utilizam a língua inglesa como lingua franca e a tradução mais comum entre aqueles que interagem em português.

Embora a maioria das professoras declare trabalhar com a AC, os dados indicam que sua abordagem possui muitas características de uma "abordagem tradicional de ensino" (O'MAGGIO, 1986; BROWN, 1994). Dessa forma, o modo pelo qual as professoras lidam com o vocabulário também é influenciado pelos princípios da abordagem tradicional. Outra característica marcante em todos os contextos, e que também causa um reflexo muito forte no ensino do vocabulário, é o fato de as professoras ficarem "presas" ao conteúdo do livro didático (LD), reproduzindo, portanto, o pequeno enfoque dispensado ao vocabulário.

\section{ESTUDO DE CASO}

Terminado o estudo exploratório, optou-se por realizar a coleta de dados para o estudo de caso no contexto universitário, mais especificamente na turma do $2^{\circ}$ ano, pois foi neste contexto que se observou uma maior preocupação com questões relacionadas ao vocabulário. A análise do estudo de caso foi dividida em cinco seções para facilitar a leitura e a compreensão, uma vez que cada seção trata de um aspecto específico que se relaciona direta ou indiretamente com o ensino de vocabulário. 


\subsection{A abordagem de $P$}

Como o ensino do vocabulário é uma parte constituinte da aula do professor, o modo de trabalhá-lo, em sala de aula, está intimamente ligado à abordagem utilizada pelo professor. Embora P tenha declarado adotar uma abordagem comunicativa, as observações das aulas mostram que a professora tem tendências de centralizar as aulas e, muitas vezes, o foco torna-se puramente gramatical, deixando sua abordagem mais próxima da tradicional. A professora passa a se preocupar mais com a precisão que com o conteúdo ou com a fluência da produção dos alunos, como pressupõe a AC (BROWN, 1994).

Nas aulas de P, a gramática é, geralmente, ensinada com o apoio do LD, e P parece bastante presa a ele e ao seu conteúdo programático. Essa minha percepção foi confirmada em um dos diários de P, quando ela diz: “... eu quis terminar o conteúdo gramatical do curso e não dei atenção ao vocabulário" (Diário de P, 28/11/2002). Embora P admita isso em seu diário do final do mês de novembro, a mesma conduta pode ser observada em aulas anteriores. As aulas parecem ser preparadas não em função das necessidades de seus alunos, mas do conteúdo programático que ela tem de cumprir.

Com o intuito de ilustrar essa prática de $\mathrm{P}$, foi selecionada, para esta análise, uma atividade de preparação para um exercício de compreensão oral. Essa atividade foi escolhida porque, ao compará-la com outras atividades desenvolvidas durante o semestre, o modo pelo qual a professora a conduziu pode ser considerado típico.

O vocabulário da aula selecionada está relacionado com a descrição de uma cidade. Em seu diário, a professora diz que o vocabulário ensinado na aula estava "associado ao tópico da lição". Na primeira atividade proposta, P distribuiu alguns cartões com fotos de várias cidades brasileiras e estrangeiras. Os alunos tinham que inventar uma história descrevendo as fotos que possuíam. Essa atividade apresentou alguns problemas, pois vários alunos ficaram confusos, por possuírem fotos de lugares díspares (uma praia e uma cidade com vários arranha-céus). Inicialmente, parecia que a atividade tinha como objetivo elicitar vocabulário para o exercício de compreensão oral, que seria realizado a seguir, mas a professora pediu para que os alunos fossem anotando os erros gramaticais cometidos pelos seus colegas em suas falas em LE. Além disso, não foi dado nenhum enfoque sobre o vocabulário de que o aluno precisaria para fazer as descrições necessárias e realizar a atividade.

Essa falta de preparação do vocabulário fez com que alguns alunos se intimidassem e não realizassem a tarefa adequadamente. Como inferimos a partir da leitura de Brown e Yule (1989), é necessário que o aluno tenha o conhecimento lexical necessário para a realização bem sucedida de uma tarefa.

\subsection{O perfil e a variação lexical da fala de alunos}

Foram realizadas duas avaliações orais, uma no início e outra dois meses após o término da coleta de dados. Ambas as avaliações foram gravadas em vídeo e, posteriormente, transcritas. A transcrição foi analisada com o auxílio de um programa de computador que 
RODRIGUES - Um olhar crítico sobre o ensino de vocabulário...

fornece o perfil lexical do texto analisado (VocabProfile). A análise feita pelo programa permite obter respostas sobre vários aspectos do vocabulário, como sua extensão, ou quais as palavras em um texto que um aprendiz pode não saber. No entanto, ao utilizar o programa como auxílio para a análise, busquei verificar a riqueza do vocabulário do estudante de línguas.

Com posse dos resultados obtidos por meio do VocabProfile, foi feita uma análise estatística dos dados, aplicando o teste-t com o objetivo de verificar se o perfil lexical do aluno melhorou durante o semestre e se houve variação lexical nas duas avaliações. A metodologia empregada nessa análise foi baseada no trabalho realizado por Laufer (1994), no qual a autora compara o perfil lexical de composições de alunos de inglês como LE.

A tabela 1 resume o desempenho dos alunos no primeiro e no segundo teste, calculando a média das porcentagens de palavras utilizadas em cada uma das listas, bem como o desvio padrão dessa média. Analisando os resultados do desvio padrão do primeiro e do segundo teste, percebe-se que ele é maior em todas as listas no segundo momento. Isso indica que a heterogeneidade do grupo cresceu com o decorrer do semestre, ou seja, a diferença do perfil lexical entre os alunos aumentou.

Tabela 1: Resultados do Perfil de Freqüência Lexical

\begin{tabular}{|c|c|c|c|c|c|c|c|c|}
\hline & \multicolumn{9}{|c|}{$\mathbf{1}^{\text {a }}$ Prova } & \multicolumn{4}{|c|}{$\mathbf{2}^{\mathbf{a}}$ Prova } \\
\hline Aluno & L 1 & L 2 & L 3 & Nenhum & L & L 2 & L 3 & Nenhum \\
\hline F & 93.5 & 4.3 & 1.2 & 1.0 & 92.6 & 3.3 & 0.2 & 3.8 \\
\hline LD & 94.5 & 3.1 & 0.7 & 1.7 & 94.7 & 2.2 & 1.4 & 1.6 \\
\hline AL & 93.1 & 3.0 & 1.0 & 3.0 & 88.3 & 5.7 & 0.8 & 5.2 \\
\hline SO & 91.3 & 5.4 & 0.8 & 2.5 & 92.0 & 3.8 & 0.7 & 3.5 \\
\hline M & 94.9 & 2.6 & 1.3 & 1.2 & 88.5 & 5.6 & 0.8 & 5.1 \\
\hline Média & 93.46 & 3.68 & 1.00 & 1.88 & 91.22 & 4.12 & 0.78 & 3.84 \\
\hline D.P. & 1.41 & 1.15 & 0.255 & 0.853 & 2.76 & 1.512 & 0.427 & 1.464 \\
\hline
\end{tabular}

Portanto, pode-se concluir que houve variação apenas entre as palavras que não constavam de nenhuma lista. Esse resultado, embora positivo, deve ser analisado com certo cuidado. Primeiro, porque a tendência geral no decorrer do processo de aprendizagem de vocabulário é que o uso de palavras básicas diminua e que elas sejam substituídas por palavras mais avançadas, o que indica o progresso no vocabulário produtivo do aluno. Embora os alunos tenham aumentado o número de palavras utilizadas que não constavam dentre as mais básicas, não foi verificada uma redução significativa do uso destas.

A tabela 2 mostra os resultados obtidos com o tratamento estatístico, realizado a partir dos dados das duas avaliações a fim de verificar se houve variação lexical entre esses dois momentos. Como $\mathrm{P}=0.1605>0.05$, então aceito a hipótese de que a média de antes é igual à média de depois, por isso concluímos que não houve variação lexical. 
Trabalhos em Lingüística Aplicada 45(1) - Jan./Jun. 2006

Tabela 2: Variação lexical

\begin{tabular}{|c|c|c|c|c|c|c|c|c|c|c|}
\hline & \multicolumn{4}{|c|}{$1^{\text {a }}$ Prova } & \multicolumn{4}{|c|}{$2^{\mathrm{a}}$ Prova } & \multirow[b]{2}{*}{ Test $\mathbf{t}$} & \multirow[b]{2}{*}{$\mathbf{P}$} \\
\hline Aluno & Type & Token & Typ/tok & Porc. & Type & Token & Typ/tok & Porc. & & \\
\hline $\mathbf{F}$ & 177 & 493 & 0.3590 & 35.90 & 130 & 390 & 0.3333 & 33.33 & & \\
\hline LD & 190 & 584 & 0.3253 & 32.53 & 163 & 465 & 0.3505 & 35.05 & & \\
\hline $\mathbf{A L}$ & 123 & 305 & 0.4033 & 40.33 & 102 & 341 & 0.2991 & 29.91 & & \\
\hline So & 179 & 520 & 0.3442 & 34.42 & 186 & 657 & 0.2831 & 28.31 & & \\
\hline \multirow[t]{3}{*}{ M } & 212 & 742 & 0.2857 & 28.57 & 179 & 762 & 0.2349 & 23.49 & & \\
\hline & \multicolumn{3}{|c|}{ MÉDIA } & 34.35 & \multicolumn{3}{|c|}{ MÉDIA } & 30.02 & \multirow[t]{2}{*}{1.5468} & \multirow[t]{2}{*}{0.1605} \\
\hline & Desv. & & & 4.33 & \multicolumn{3}{|c|}{ Desv. Pad. } & 4.52 & & \\
\hline
\end{tabular}

A capacidade de variar as palavras utilizadas para se expressar pode ser considerada um aspecto que indica o desenvolvimento lexical do aluno. Logo, a ausência de variação lexical entre os semestres nos leva a concluir que não houve, de fato, muita aprendizagem de vocabulário pelos alunos participantes desse estudo.

\subsection{As estratégias de ensino de vocabulário}

Quando falamos de estratégias de ensino, lembramos imediatamente do professor. No entanto, é importante ressaltar que não foi apenas $\mathrm{P}$ quem fez uso das estratégias de ensino de vocabulário, já que os alunos desse contexto eram constantemente chamados, pela professora, a fornecer explicações a seus colegas, como será explicado a seguir.

Os dados mostram que são três os momentos mais freqüentes para discussão sobre o significado das palavras desconhecidas. O primeiro deles, e o mais freqüente, é a discussão de vocabulário durante a leitura de texto em sala de aula. Analisando esse tipo de abordagem para o debate do texto, percebe-se que ela não é muito eficaz quando aborda um texto com a finalidade de ensinar leitura, uma vez que faz com que os alunos se prendam a todas as palavras desconhecidas, além de não estimular o uso da inferência por meio do contexto. Além disso, o foco da atividade deixa de ser a compreensão do texto.

O segundo momento é a realização do exercício vocabulary, do livro didático. A cada unidade, esse exercício enfoca um aspecto diferente sobre o vocabulário (nomes compostos, adjetivos descritivos, substantivação ou adjetivação de um verbo). Esse exercício é geralmente trabalhado em pares ou grupos, e, posteriormente, discutido com a classe toda. Mais uma vez, discute-se palavra por palavra, freqüentemente de forma descontextualizada. As palavras discutidas não são utilizadas para um fim prático, uma vez que não é proposta nenhuma atividade de produção que as utilize. $\mathrm{O}$ aluno simplesmente completa o exercício proposto, faz a discussão, e a atividade é dada por encerrada. $\mathrm{O}$ grande problema é justamente este pois sem o uso efetivo de uma palavra, ela terá poucas chances de ser adquirida pelo aluno.

O terceiro momento, menos freqüente, ocorre durante as discussões em pares ou grupos - mais especificamente quando um aluno quer utilizar alguma palavra que não conhece. Geralmente, ele pede auxílio à professora, embora, às vezes, também seja ajudado 
pelos próprios colegas. A busca de auxílio é uma estratégia de aprendizagem social importante, pois faz com que o aluno possa interagir na língua-alvo. No entanto, muitas vezes os alunos utilizavam a língua materna em momentos como esse, fazendo com que sua fluência em LE fosse interrompida. Muitas dessas dúvidas poderiam ter sido evitadas, caso a professora tivesse realizado uma atividade de aquecimento para o exercício em questão, em que ela trabalharia parte do vocabulário necessário para o desempenho da tarefa.

Como se pode perceber, o vocabulário foi trabalhado em situações específicas com o objetivo maior de apenas esclarecer o significado, e não de aquisição propriamente dita. Não foi proposta, durante o semestre, nenhuma atividade que visasse a retenção de vocabulário para fins produtivos.

A seguir, faço um levantamento de quais foram as estratégias utilizadas pela professora e pelos alunos para esclarecer o significado das palavras quando as dúvidas surgiam em sala de aula. Esse levantamento contribui para área de pesquisa na qual esse trabalho se insere, pois, como afirmam Carter e McCarthy (1988: 51) "faltam estudos que observem o que acontece na sala de aula quando surgem problemas com o vocabulário ${ }^{3}$ ". Embora $o$ texto deles já tenha mais de dez anos, não encontrei, em meu levantamento bibliográfico, pesquisas que abordassem essa questão.

\subsubsection{Classificação das estratégias de ensino de vocabulário}

Para verificar quais foram as estratégias utilizadas pela professora e pelos alunos para o ensino de vocabulário, assisti às gravações das aulas, observando os momentos em que o vocabulário foi trabalhado. As explicações foram transcritas e classificadas. Não havia uma taxonomia previamente estabelecida para a categorização das estratégias de ensino; elas foram criadas a partir dos exemplos levantados. Além das transcrições, também são considerados a análise os dados obtidos por meio das entrevistas e dos diários dos participantes e do pesquisador. Foram consideradas tanto as estratégias utilizadas pela professora quanto as usadas pelos alunos para explicar alguma palavra para o grupo ou para um aluno específico, durante as aulas. As estratégias encontradas foram as seguintes: paráfrase, tradução, exemplificação, sinonímia, gestos, recursos visuais, associação, correção, imitação, soletração, cognato, gramática, pronúncia, antonímia e inferência.

A tradução ocorre, geralmente, quando um aluno, durante a interação, não sabe como dizer alguma palavra e pergunta para a professora como se diz a palavra em inglês. Para não quebrar a fluência da interação, a professora oferece a tradução ao aluno para que ele possa prosseguir. Observe o fragmento 1:

\footnotetext{
${ }^{3}$ No original: "What is perhaps missing in all this is more knowledge about what happens when vocabulary crops up".
} 


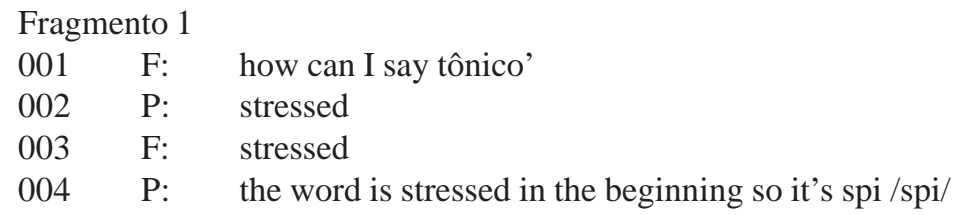

A aluna estava discutindo a pronúncia da palavra spinach. Durante a discussão, ela não sabia perguntar qual sílaba da palavra era tônica, o que a levou a perguntar para professora como se diz tônico em inglês. A professora oferece a tradução imediata e a aluna a confirma. Em geral, essa estratégia sempre ocorre em situações semelhantes e seus movimentos são parecidos. Primeiro, a elicitação, em seguida, a resposta e, por fim, a confirmação.

Os gestos foram bastante comuns nas aulas, tanto por parte da professora quanto dos alunos. Geralmente, eram acompanhados por uma explicação para a palavra e tinham um valor mais ilustrativo. Verifiquei que alguns alunos utilizavam os gestos tanto como estratégia de ensino de vocabulário para um amigo, quanto como estratégia própria de aprendizagem. $\mathrm{O}$ aluno SO, em especial, se mostrou bastante cinestésico e estava sempre dando exemplos com o auxílio de gestos. Segundo SO, quando ele aprende uma palavra e a associa a um gesto, não a esquece mais. $\mathrm{O}$ fragmento 2 mostra uma situação em que a professora utilizou os gestos como estratégia de ensino:

\section{Fragmento 2}

001 A: what's to iron?

002 P: it's when you take an iron and iron your clothes (( faz gestos ))

A utilização da sinonímia se baseia no conhecimento que o aluno tem de outras palavras que pertençam ao mesmo campo semântico da palavra que está sendo explicada. A vantagem dessa estratégia é ativar outras palavras, conhecidas pelos alunos, durante a explicação. A desvantagem ocorre quando o aluno ou o professor interpreta o sinônimo oferecido como sendo "perfeito" e usa a palavra nova como se fosse idêntica à oferecida. O equívoco se torna um problema, pois, como se sabe, nunca existirá uma palavra que tenha $100 \%$ das características de uma outra, já que, como explica McCarthy (1990), duas palavras podem: 1. ter significados próximos, mas terem colocação ou comportamento sintático diferentes, 2. pertencer a contextos ou situações diferentes, 3. serem separadas de acordo com a distribuição geográfica, e 4. ser uma mais arcaica que a outra. Logo, acredito ser importante explicar para o aluno o traço diferenciador entre as palavras, como propõem McCarthy (1990) e Channel (1981), para que eles possam usá-la nos contextos mais adequados.

A correção foi usada, algumas vezes, com o propósito de ensinar o vocabulário de uma determinada lição; e foi verificada apenas na fala da professora. Ela acontece quando o aluno utiliza uma palavra errada para se expressar e a professora oferece, como sugestão, a palavra correta. Como pôde ser verificado anteriormente na seção sobre a abordagem de $\mathrm{P}$, ela tem uma certa tendência a corrigir os alunos imediatamente após os erros. $\mathrm{O}$ fato de 
RODRIGUES - Um olhar crítico sobre o ensino de vocabulário...

ter utilizado essa estratégia para o vocabulário apenas quatro vezes durante todo o semestre todo pode indicar que ela não o considera tão importante quanto a gramática, uma vez que seu objetivo, com a correção, era praticar as estruturas corretas para que não houvesse uma assimilação da forma errônea. No fragmento 3, P chama a atenção para o uso da palavra boring em vez de bothering.

Fragemento 3

001 M: my preferred room at my house is + the bedroom + erm well it's the place where I can study where I can read some books + and it's the only + place at home that I can + stand alone + nobody boring me ++ I just close the door and nobody

$002 \quad \mathrm{P}: \quad$ bothering me

$003 \mathrm{M}$ : bothering me

A paráfrase também é uma das estratégias de ensino mais utilizadas pela professora e pelos alunos, assim como a tradução. A paráfrase é bastante comum quando existe alguma palavra em um dos exercícios do livro que a professora julga relevante para o entendimento da tarefa. Neste caso, a definição oferecida é, geralmente, parecida com a entrada do verbete no dicionário, ou seja, bastante detalhada e específica. Nas interações, essa estratégia é usada tanto pela professora quanto pelos alunos para ensinar os colegas. No caso dos alunos, as paráfrases eram menos detalhadas e serviam para um esclarecimento mais geral sobre a palavra. $\mathrm{O}$ fragmento 4 traz um exemplo do uso da paráfrase utilizada pela professora para explicar a palavra barren.

\section{Fragmento 4}

$001 \quad$ P: $\quad$ barren is a desert land (+) almost infertile (+) where nothing grows

A explicação gramatical consiste em dar explicações sobre a formação de uma palavra (sufixos, prefixos, radical) ou sobre sua classe gramatical, a fim de esclarecer seu significado para os alunos. Em uma das aulas, por exemplo, a professora pediu para que SO explicasse para o grupo a palavra wilderness. O aluno iniciou sua explicação perguntando a seus colegas se eles conheciam o significado da palavra wild. Como a resposta foi afirmativa, ele disse então que wild é o adjetivo e wilderness, o substantivo. A explicação de SO foi bastante eficiente, pois relacionou uma palavra nova com uma outra palavra conhecida pelos alunos, que possui o mesmo radical. Todos compreenderam a explicação de SO. Esta estratégia faz o aluno refletir sobre a própria palavra, sobre sua formação. Embora tenha sempre resultados positivos quando usada, esta estratégia não é muito comum nas aulas analisadas.

A estratégia denominada recursos visuais compreende o uso de fotos, gravuras, desenhos, objetos reais e/ou vídeo para fornecer o insumo necessário para a compreensão do vocabulário. Esta estratégia é, geralmente, bastante eficiente, pois o aluno consegue entender a palavra que está sendo explicada imediatamente, economizando o tempo que 
se gastaria com explicações laboriosas. Seu uso é importante por existirem alunos com uma capacidade de associação visual muito grande, o que facilita a aprendizagem do vocabulário por meio desta estratégia. No entanto, é importante ressaltar que o professor deve estar atento às limitações dos recursos visuais em determinadas situações, pois, como explica McCarthy (1990, p. 115), "nem todas as palavras são facilmente explicadas por meio de estímulo visual, e os estímulos visuais também podem levar a interpretações erradas $^{4}$ ".

A exemplificação consiste na explicação da palavra por meio de um exemplo. A diferença entre a paráfrase e a exemplificação é que aquela define a palavra desconhecida, enquanto que esta a ilustra em uma situação de uso. Essa estratégia foi a terceira mais usada nesse contexto e, raramente, ocorria sozinha; geralmente, era utilizada acompanhada de uma paráfrase, a fim de ilustrar a definição, da mesma forma que acontece nos dicionários monolíngues. No fragmento 5, temos um exemplo do uso dessa estratégia para explicar a palavra trial. Em vez de definir a palavra, a professora opta por descrever um contexto de uso:

Fragmento 5

042 P: (...) and the +++ trial + do you understand this word? (4 seg.) yes' + no? + when you go to ++ you are a magistrate + you know the word + going to freedom ++ you are arrested and want the freedom + so you have a trial to see if you are guilty ++ or not + yes?

A imitação consiste em tentar reproduzir uma característica determinante da palavra que se quer explicar. O exemplo mostrado no fragmento 29 ilustra bem o uso dessa estratégia. Quando uma das alunas decidiu perguntar o significado da palavra sheep, sobre a qual a professora estava se referindo a algum tempo em sua fala, P simplesmente imitou o som desse animal, eliminando a dúvida da aluna e até causando uma certa descontração entre os alunos que riram ao ouvir a professora imitando uma ovelha. Por ser uma estratégia que exige um certo grau de desenvoltura, ela foi utilizada apenas pela professora. Os alunos, geralmente, são bastante tímidos e sentem medo de uma possível exposição ao ridículo em uma situação dessas, optando por outras estratégias.

$\mathrm{O}$ uso de palavras cognatas foi considerado uma estratégia de ensino do vocabulário porque a professora explicou três palavras dizendo apenas que o significado delas em inglês era o mesmo que em português, já que havia uma grande semelhança gráfica entre elas. No fragmento 6, temos um exemplo do uso desta estratégia para explicar o significado das palavras terrible e horrendous. Em vez de explicar as palavras utilizando uma paráfrase, um sinônimo ou uma exemplificação, $\mathrm{P}$ optou por dizer que elas significam o mesmo que em português, já que pela grafia era possível associa-las às palavras terrível e horrendo:

${ }^{4}$ No original: "not all words are easily explained by a visual stimulus, and visual stimuli can be misleading". 
RODRIGUES - Um olhar crítico sobre o ensino de vocabulário...

Fragmento 6

$001 \quad$ P: $\quad$ When there are crimes they are horrendous $(+)$ terribles $($ sic $)(+)$ yes' okay' the same words in Portuguese (+) okay'

Algumas vezes, P utilizou a pronúncia de algumas palavras como forma de explicálas e diferenciá-las de outras, com pronúncia semelhante. Essa estratégia se faz importante, especialmente quando as palavras em LE possuem sons semelhantes, pois estudos indicam, que, neste caso, os alunos costumam confundi-las (Laufer, 1997). No fragmento 7, temos um exemplo no qual a professora usou a fonética para explicar a diferença da pronúncia entre duas palavras, high e height. Na aula anterior, $\mathrm{P}$ e os alunos utilizaram a palavra height em situações em que deveria ser usada a palavra high:

Fragmento 7

181 P: okay look $\{$ HES $\}$ hum at the board look at the board please ++ last class I had done something in a wrong way and nobody corrected me yes? + so let's come back to this + high + is different from height + this has a T sound this one doesn't have ++ so how $\{$ HES $\}$ so how can I write that? ((escreve na lousa /hai/ e /hait/)) (9 seg.) (incomp.) yes? this one (5 seg.) okay?

É denominada antonímia a estratégia que consiste no uso de antônimos para a explicação do vocabulário desconhecido. Para que o uso dessa estratégia seja eficaz, o professor deve ter um bom conhecimento do nível lexical de seus alunos, para que possa utilizar um antônimo que eles já conheçam. A opção por uma palavra desconhecida pode levar os alunos a não compreender a palavra nova. McCarthy (1990) chama atenção também para outro ponto: ao se utilizar a antonímia como estratégia para ensinar vocabulário, os alunos devem estar cientes de que uma palavra pode ter opostos diferentes em diferentes contextos. Com isso, ele ressalta a importância de se estabelecer o contexto de uso da palavra ao ensiná-la e estudá-la. A palavra light, por exemplo, pode ter como antônimo as palavras heavy, strong ou dark (pesado, forte, escuro), dependendo do contexto em que é utilizada.

A associação consiste em uma organização semântica das palavras, formando uma "rede" de significados. Essa estratégia é bastante complexa, pois envolve o conhecimento de mundo de quem a utiliza. McCarthy (1990) argumenta que ao relacionar as palavras com o conhecimento de mundo, a associação se torna muito mais que uma simples utilização de informações semânticas.

Bem simples de ser compreendida, a estratégia de soletrar foi utilizada basicamente para ensinar o aluno a escrever alguma palavra que estava sendo discutida. Essa estratégia foi a única não utilizada durante a explicação de palavras dos textos de leitura, uma vez que as palavras já se encontram escritas nesses exercícios, não havendo dúvidas com relação à sua ortografia. 
A inferência é uma das estratégias de aprendizagem mais comumente utilizadas pelos alunos (McCarthy, 1990). No contexto observado, no entanto, verificou-se algo interessante, o uso da inferência como estratégia de ensino. A inferência envolve a criação de um esquema para a explicação de uma palavra desconhecida, baseada no conhecimento e experiência prévios, tanto do mundo quanto do texto. Significa tirar conclusões do significado de uma palavra, seguindo uma certa linha de raciocínio traçada por meio das evidências disponíveis. A inferência só foi verificada como estratégia de ensino em virtude do modo pelo qual $\mathrm{P}$ trabalha o vocabulário em sala de aula, a partir dos textos de leitura.

Durante as 26 aulas em que houve explicação de vocabulário, foram trabalhadas 198 palavras diferentes. Para tanto, foi utilizado um total de 317 explicações lexicais, dadas tanto pelos alunos quanto pela professora. Os dados demonstram que, na maioria das vezes, a explicação de um vocábulo requeria a utilização de mais de uma estratégia de ensino. Todas essas explicações foram transcritas e categorizadas, tendo sido encontrado um total de 15 estratégias diferentes. A tabela a seguir mostra os tipos e a freqüência de uso das estratégias no corpus analisado:

Tabela 3: Frequiência de uso das estratégias de ensino de vocabulário

\begin{tabular}{|l|c|c|c|c|}
\hline Estratégia & Utilizações & Porcentagem & Usos por P & Usos por A \\
\hline paráfrase & 127 & $40 \%$ & 65 & 62 \\
\hline tradução & 54 & $17 \%$ & 20 & 34 \\
\hline exemplificação & 46 & $14,5 \%$ & 34 & 12 \\
\hline sinonímia & 29 & $9,15 \%$ & 10 & 19 \\
\hline gestos & 15 & $4,73 \%$ & 5 & 10 \\
\hline recursos visuais & 11 & $3,5 \%$ & 9 & 2 \\
\hline associação & 10 & $3,15 \%$ & 7 & 3 \\
\hline correção & 4 & $1,26 \%$ & 4 & 0 \\
\hline imitação & 4 & $1,26 \%$ & 4 & 0 \\
\hline soletração & 4 & $1,26 \%$ & 2 & 2 \\
\hline cognato & 3 & $0,946 \%$ & 3 & 0 \\
\hline gramática & 3 & $0,946 \%$ & 1 & 2 \\
\hline pronúncia & 3 & $0,946 \%$ & 3 & 0 \\
\hline antonímia & 2 & $0,63 \%$ & 1 & 1 \\
\hline inferência & 2 & $0,63 \%$ & 2 & 0 \\
\hline TOTAL & 317 & $99,9 \%$ & 170 & 147 \\
\hline
\end{tabular}

Embora aparentemente haja uma certa diversidade no uso de tais estratégias, mais de $70 \%$ das explicações correspondem a apenas 3 tipos de estratégias: paráfrase, tradução e exemplificação. Isso indica que não há uma variação na escolha da estratégia a ser utilizada, o que pode ter desfavorecido a aprendizagem de algumas palavras. O estudo de Schimtt (1997) e os dados desta pesquisa indicam que os alunos estariam dispostos a utilizar novas estratégias se o professor se dispusesse a ensiná-las. Uma maior diversificação, portanto, 
favoreceria a aprendizagem dos alunos, uma vez que propiciaria o estabelecimento de diferentes relações mentais com as palavras novas.

Das 317 estratégias analisadas, $170(54 \%)$ foram utilizadas pela professora enquanto que 147 (46\%), pelos alunos. Foi possível perceber que os alunos têm uma participação muito importante durante a explicação do vocabulário, participando ativamente desta tarefa. Os dados mostram que os alunos mais proficientes foram os que mais explicaram as palavras novas levantadas durante as aulas, mesmo havendo a intenção de distribuição por parte da professora. Apenas dois alunos (F e SO) foram responsáveis pela utilização de $40 \%$ de todas as estratégias usadas pelos estudantes.

Tanto a professora quanto os alunos utilizam mais a paráfrase para suas explicações. De acordo com Allen (1983), essa capacidade de definir palavras por meio de outras palavras mais simples é uma técnica necessária aos professores. No entanto, a autora, afirma que é o professor e não o aluno que deve usar a frase com a definição, pois a capacidade de usar a palavra comunicativamente é mais importante que a sua definição. Como as aulas foram coletadas em um contexto que forma futuros professores de línguas, o grande uso da paráfrase pelos alunos pode ser justificado como uma prática para sua futura profissão.

No entanto, há algumas diferenças interessantes a serem discutidas. $\mathrm{O}$ uso de exemplificações, por exemplo, é bastante comum pela professora e nem tanto pelos alunos, possivelmente até pela complexidade que a elaboração de um exemplo contextualizado exige. Já o uso da tradução, de gestos e de sinonímia é muito maior pelos alunos do que pela professora.

Algumas estratégias também foram utilizadas apenas pela professora, como é o caso do uso de figuras, de desenhos, da inferência, da imitação, entre outros. Embora tenham sido pouco utilizadas, a simples constatação do uso dessas estratégias já indica que a professora, ao contrário do que declarou em seus diários, conhece várias estratégias para o ensino do vocabulário. A questão da sua baixa frequiência de uso não está relacionada, portanto, à falta de conhecimento das estratégias, mas ao modo de abordar o vocabulário em sala de aula.

\section{CONSIDERAÇÕES FINAIS}

Este trabalho procurou fazer uma descrição das estratégias de ensino e aprendizagem de vocabulário, que foram levantadas a partir das interações em sala de aula. Como se pode observar no capítulo de análise, embora o levantamento tenha encontrado uma certa diversidade com relação ao número de estratégias (15), a frequiência de uso dessas estratégias foi bastante concentrada $(70 \%$ do uso correspondendo apenas às três estratégias mais usadas).

Como os alunos relataram no questionário que a falta de estratégias para aprender o vocabulário torna essa tarefa "chata e desestimulante", uma maior variedade na freqüência de uso dessas estratégias pode beneficiar o aprendiz. Também poderiam ser definidos alguns momentos para explicação do vocabulário necessário para o desenvolvimento das 
atividades de conversação propostas. Isso faria com que os alunos pudessem utilizar o vocabulário ensinado previamente, como suporte para sua comunicação, favorecendo o enriquecimento lexical da fala do aluno.

A paráfrase foi a estratégia mais utilizada nesse contexto, o que, por se tratar de um contexto de nível intermediário, era esperado. Como diz Allen (1983), muitas palavras do curso intermediário não podem ser explicadas por meio de ações ou fotos, mas sim por meio de explicações, inserindo-as em frases nas quais as outras palavras já sejam conhecidas dos alunos. No entanto, a mesma autora afirma que quem deve fornecer a frase com a definição da palavra é o professor e não o aluno. Nesse contexto, porém, observou-se um uso bastante equilibrado dessa estratégia entre alunos e professor, tendo sido utilizada 62 e 65 vezes por cada um, respectivamente. Como já discutido anteriormente, uma possível explicação para isso pode ser o fato dessa turma ser composta por alunos que serão futuros professores e que terão que fornecer definições a seus alunos. Dessa forma, P pode estar objetivando prepará-los para a atividade docente, expondo-os a situações semelhantes a que poderão encontrar futuramente.

O resultado dos testes orais, realizados com os alunos a fim de observar o grau de retenção das palavras aprendidas e o desenvolvimento do seu perfil lexical, indica que há, de fato, problemas com a abordagem adotada pela professora no que se refere ao ensino de vocabulário, pois os alunos não melhoraram seu perfil lexical de um semestre para outro. Assim, pode-se inferir que explicar uma palavra que o aluno desconheça em sala de aula resolve o problema de compreensão no momento, mas não faz com que o aluno aprenda aquela palavra.

Cabe ao professor incluir o vocabulário nas suas preocupações ao preparar suas aulas, propondo atividades em que determinadas palavras consideradas chave sejam explicitamente ensinadas. Dessa forma, o professor chama a atenção do aluno para aquelas palavras, possibilitando uma maior discussão e reflexão sobre elas, o que é imprescindível para facilitar sua retenção.

Discordo do argumento de que explicar o vocabulário explicitamente seja uma perda grande de tempo já que algumas pesquisas indicam que é reduzido o número de palavras que um aluno consegue efetivamente aprender em cada aula. Como foi possível de se observar por meio desta investigação, sem um trabalho que focalize explicitamente as palavras, também não há um acréscimo de palavras no vocabulário ativo-livre do aluno. Além disso, muitas vezes, as explicações que a professora tinha que dar, para algumas palavras tomavam muito tempo da aula. É importante ainda lembrar que essas pesquisas cujos resultados não apóiam o ensino explícito de vocabulário são realizadas em contexto de ISL e não de ILE, que é o caso no Brasil. A pesquisa de mestrado de Zilles (2001) comparou a retenção de algumas palavras por dois grupos de alunos: um em que as palavras tinham sido trabalhadas de modo implícito e outro em que as mesmas palavras tinham sido trabalhadas de modo explícito. Os resultados dessa pesquisa indicam que o contexto em que o ensino explícito foi adotado obteve um índice de retenção muito superior, o que confirma que, em contexto de ILE, essa é uma alternativa viável. 
Os dados analisados para esta pesquisa também podem levantar muitas outras perguntas, que ainda podem ser feitas a respeito do uso das estratégias de ensino e aprendizagem de vocabulário em aulas de LE, como, por exemplo, se existe uma relação entre o nível dos alunos e o tipo de estratégia utilizada. Acredito que este passo inicial tenha sido muito importante para que nós, pesquisadores, professores e alunos, voltemos a refletir sobre esse aspecto tão importante para o ensino de línguas, que é o ensino de vocabulário.

\section{REFERÊNCIAS BIBLIOGRÁFICAS}

ALLEN, V. F. (1983). Techniques in Teaching Vocabulary. Hong Kong: OUP.

BOWEN, T.; MARKS, J. (1994). Inside Teaching. Londres: Heinemann.

BROWN, D. H. (1994). Teaching by Principles: an Interactional Approach to Language Pedagogy. Englewood Cliffs: Prentice Hall Regents.

BROWN, G.; YULE, G. (1989). Teaching the spoken language: an approach based on the analysis of conversational English. Cambridge: CUP.

CARTER, R., McCARTHY. (1988). Vocabulary and language teaching. Nova York: Longman.

CHANNEL, J. (1981). Applying semantic theory to vocabulary teaching. ELT Journal, v. 35, n. 2, p. 115-22.

GATTOLIN, S. R. B. (1998). O ensino de vocabulário em língua estrangeira: uma proposta para sua sistematização. Dissertação (Mestrado em Lingüística Aplicada), IEL, Universidade Estadual de Campinas: Campinas.

LAUFER, B. (1998). The Development of passive and active vocabulary in a second language: same or different? Applied Linguistics, Oxford, v. 19, n. 2, p. 255-271.

. (1994). The lexical profile of second language writing: does it change over time? RELC Journal. v. 25, n. 2, p. 21-33.

(1997). What's in a word that makes it hard or easy? Some intralexical factors that affect the learning of words. In: SCHMITT, N.; McCARTHY, M. Vocabulary: description, acquisition and pedagogy. Cambridge: CUP, cap. 2.3, p. 140-55.

LAUFER, B.; NATION, P. (1995). Vocabulary Size and Use: Lexical Richness in L2 Written Production. Applied Linguistics, Oxford, v. 16, n. 3, p. 307-322.

LEFFA, V. J. (Org.) (2000). As palavras e sua companhia: o léxico na aprendizagem. Pelotas: Educat.

MCCARTHY, M. (1990). Vocabulary. Oxford: OUP.

MEARA, P. (1984). The Study of Lexis in Interlanguage. In: DAVIS, A. et al. (Orgs.) Interlanguage. Edingurgh: Edinburgh University Press, cap. 20, p. 225-235.

NATION, P. (2001). Learning vocabulary in another language. Cambridge: CUP.

O'MAGGiO, A. C. (1986). Teaching Language in Context: Proficiency Oriented Instruction. Boston, MA: Heinle \& Heinle Publishers. 
SCARAMUCCI, M. V. R. (1995). O papel do léxico na compreensão em leitura em língua estrangeira: foco no produto e no processo. Tese (Doutorado em Linguística Aplicada), IEL, Universidade Estadual de Campinas: Campinas.

SCHMITT, N. (1997). Vocabulary learning strategies. In: SCHMITT, N.; McCARTHY, M. Vocabulary: description, acquisition and pedagogy. Cambridge: CUP, p. 199-227.

ZILLES, M. (2001). O ensino e a aquisição de vocabulário em contexto de instrução de língua estrangeira. Dissertação (Mestrado em Estudos da Linguagem) - UFRS, Universidade Federal do Rio Grande do Sul, Porto Alegre. 